\title{
Association between Chronic Mental Stress and Academic Performance among Korean Adolescents
}

\author{
Asociación entre estrés mental crónico y desempeño \\ académico en adolescentes koreanos
}

Recibido: 24 de abril de 2014 | Revisado: 26 de marzo de 2015 | Aceptado: 26 de marzo de 2015

\author{
SUN-KYUNG LEE ** \\ Kong-Ju National University, Gongju, Republic of Korea \\ WI-YOUNG So *** \\ Korea National University of Transportation, Chungju-si, \\ Republic of Korea \\ DONG JUN SunG ***** \\ Konkuk University, Chungju-si, Republic of Korea
}

doi:10.11144/Javeriana.upsy14-3.abcm

Para citar este artículo: Lee SK, So, WY, \& Sung, DJ. (2015). Association between chronic mental stress and academic performance among Korean adolescents. Universitas Psychologica, 14(3), 967-974. http://dx.doi.org/10.11144/Javeriana.upsy14-3.abcm

* Researcher paper

** Researcher, Department of Education Graduate School, Kong-Ju National University, Gongju, Republic of Korea.sklee@cje.ac.kr

**** Assistant professor, Sports and Health Care Major, College of Humanities and Arts, Korea National University of Transportation, Chungju-si, Republic of Korea.wowso@swu.ac.kr

****** PhD. Assistant Professor, Division of Sport Science, College of Science and Technology, Konkuk University, Corresponding Author: 268 Chungwondaero, Chungju-si, Chungcheongbuk-do 380-701, Republic of Korea. Office: 82-43-840-3504. Fax: 82-43-840-3498. Chungju-si, Republic of Korea. E-mail: sls98@kku.ac.kr

\section{Resumen}

En este estudio se examinó si el estrés mental crónico se asocia con el rendimiento académico en adolescentes coreanos. La muestra estuvo constituida por los 74.186 adolescentes de entre el 7 y el $12^{\circ}$ grado (12-18 años) que participaron en la 8va encuesta en internet sobre Comportamiento de Riesgo en Jóvenes en 2012. Se utilizó el análisis de regresión logística multivariante para aclarar cómo el estrés crónico mental se relacionaba con el rendimiento académico después del ajuste por edad, índice de masa corporal, posición económica de la familia, el nivel de educación de los padres, la frecuencia de fumar, la frecuencia de ingesta de alcohol, y la frecuencia de la actividad física vigorosa y moderada y ejercicios de fuerza musculares. Para los varones, las personas con estrés mental crónico muy alto tenían menos probabilidades de lograr un rendimiento académico promedio o superior (odds ratio $[\mathrm{OR}]=$ 0.738, 95\% intervalo de confianza [IC]: 0.629 a 0.867, p <0,001) que aquellos con muy estrés mental baja. Para las niñas, las que tenían estrés mental muy alto tenían menos probabilidades $(\mathrm{OR}=0.668$; IC del 95\%: 0.521 - 0.857, $\mathrm{p}=0.002)$, mientras que aquellas con estrés mental bajo tenían más probabilidades (OR IC $=1.324,95 \%$ : $1.029-1.704 ; \mathrm{p}=0.029$ ) para tener un rendimiento promedio académico o superior, en comparación con las niñas con estrés muy bajo. Los grados (pruebas, exámenes de ingreso) fueron la principal causa de estrés mental crónico tanto en varones $(51.7 \%)$ y niñas (54.,8\%). Los varones y las niñas de la República de Corea de estrés mental crónico muy alto mostraron una disminución del rendimiento académico. Palabras clave

Adolescentes; Encuesta en Internet sobre Comportamiento de Riesgo en Jóvenes; Estrés mental crónico; desempeño académico

\section{A B S T R A C T}

We examined whether chronic mental stress is associated with academic performance in Korean adolescents. Our sample consisted of the 74,186 adolescents between the $7^{\text {th }}$ and $12^{\text {th }}$ grades (aged 12-18 years) who participated in the $8^{\text {th }}$ Korean Youth Risk Behavior Web-based Survey in 2012. We used multivariate logistic regression analysis to clarify how chronic mental stress was related to academic performance after adjustment for age, body mass index, family economic status, parents' education level, smoking frequency, alcohol intake frequency, and frequency of vigorous and moderate physical activity and muscular strength exercises. For boys, those with very 
high chronic mental stress were less likely to achieve average academic performance or higher (odds ratio $[\mathrm{OR}]=0.738$, $95 \%$ confidence interval $[\mathrm{CI}]: 0.629-0.867, p<0.001)$ than were those with very low mental stress. For girls, those with very high mental stress were less likely $(\mathrm{OR}=0.668,95 \%$ CI: $0.521-0.857, p=0.002)$, while those with low mental stress were more likely $(\mathrm{OR}=1.324,95 \% \mathrm{CI}$ : 1.029-1.704; $p=0.029)$ to have average academic performance or higher, compared with girls with very low stress. Grades (tests, entrance examinations) were the primary cause of chronic mental stress in both boys (51.7\%) and girls (54.8\%). Republic of Korean boys and girls with very high chronic mental stress showed decreased academic performance.

Keywords

Adolescent; Korea Youth Risk Behavior Web-based Survey;

Chronic mental stress; Academic performance

\section{Introduction}

According to the Korea Ministry of Gender Equality \& Family in 2012, 70.3\% of adolescents aged 15-19 years had high or very high chronic mental stress in their daily lives (Korea Ministry of Gender Equality \& Family, 2012). High mental stress has numerous negative effects on the body, both in the short (e.g., diarrhea, constipation, acne, migraines, lack of sleep, hives, and triggers for acute myocardial infarction) and long term (e.g., chronic fatigue, coronary artery disease, irritable bowels, depression, posttraumatic stress disorder) (Centers for Disease Control and Prevention, 2005; Cohen, Janicki-Deverts, \& Miller, 2007; Dimsdale, 2008; Pittenger \& Duman, 2008; Xu, Anwyl, \& Rowan, 1997). In addition, it is associated with increased suicide risk (Shaffer \& Craft, 1999), and, more recently, impaired cognitive functioning (particularly learning and memory) (Lupien, Maheu, Tu, Fiocco, \& Schramek, 2007) in both adults and adolescents (Eiland \& Romeo, 2012; Romeo \& McEwen, 2006).

This apparent relationship between chronic mental stress and reduced cognitive function in adolescents has important bearings on the field of education, in that chronic mental stress may lead to reduced academic performance (Sanders \& Lushington, 2002; Stewart, Lam, Betson, Wong, \& Wong, 1999). However, little research worldwide has further explored these initial findings. Moreover, existing studies on this topic used overly small sample sizes, meaning that the results cannot be generalized to the rest of the population in the studied countries. In addition, no prior studies on this topic have been conducted in Republic of Korea. Therefore, the purpose of the present study was to determine whether chronic mental stress is related to academic performance in Korean adolescents across the entire country, after controlling for various covariates.

\section{Materials and Methods}

\section{Design}

We employed data from the $8^{\text {th }}$ Korea Youth Risk Behavior Web-based Survey (KYRBWS-VIII), conducted in 2012. This cross-sectional epidemiological study aimed to identify various health risk factors in Korean adolescents by asking for relevant information thought to affect overall health (e.g., body mass index, smoking and drinking frequency). It used a complex sample design that included 129 stratifications and 43 clusters, and a multistage sampling method so that it could cover the entire country. The target sample of the KYRBWS-VIII was 400 students of each middle and high school in Republic of Korea, including students from the first year of middle school ( $7^{\text {th }}$ grade) to the third year of high school $\left(12^{\text {th }}\right.$; aged $12-18$ years). Students were assigned unique ID numbers by their classroom teachers and accessed the survey web page using those numbers. At this point, they were prompted as to whether they were willing to participate. Those students who chose to enroll in the survey anonymously completed the questionnaire at their schools. The KYRBWS-VIII did not collect any private information, such as name, social security number, school name, telephone number, or home address; as such, ethical approval was not required. The response rate was $96.4 \%$ (74,186 of 76,980 students), with 38,221 being boys and 35,965 being girls.

The details of the data collection procedure are described in greater detail elsewhere by the Ministry of Education, Science and Technology, Ministry of Health and Welfare, Korea Centers for Disease Control and Prevention (Ministry of Education, 
TABLE 1

Participant Characteristics

\begin{tabular}{|c|c|c|c|c|}
\hline \multicolumn{2}{|c|}{ Variables } & $\begin{array}{c}\text { Boys } \\
(\mathrm{n}=38,221)\end{array}$ & $\begin{array}{c}\text { Girls } \\
(\mathrm{n}=35,965)\end{array}$ & $\begin{array}{c}\text { Total } \\
(\mathrm{N}=74,186)\end{array}$ \\
\hline Age (years) & & $14.89 \pm 1.75$ & $14.89 \pm 1.76$ & $14.89 \pm 1.76$ \\
\hline Height $(\mathrm{cm})$ & & $169.08 \pm 8.39$ & $159.66 \pm 5.49$ & $164.52 \pm 8.55$ \\
\hline Weight (kg) & & $60.04 \pm 12.01$ & $51.83 \pm 7.98$ & $56.06 \pm 11.05$ \\
\hline Body mass index $(\mathrm{kg} / \mathrm{m} 2)$ & & $20.88 \pm 3.28$ & $20.29 \pm 2.67$ & $20.59 \pm 3.02$ \\
\hline \multirow{5}{*}{ Academic performance n (\%) } & Excellent & $4.547(11.9)$ & $3.373(9.4)$ & $7.920(10.7)$ \\
\hline & Good & $8.943(23.4)$ & $8.659(24.1)$ & $17.602(23.7)$ \\
\hline & Mediocre & $9.949(26)$ & $9.905(27.5)$ & $19.854(26.8)$ \\
\hline & $\mathrm{Bad}$ & $9.481(24.8)$ & $9.460(26.3)$ & $18.941(25.5)$ \\
\hline & Very bad & $5.301(13.9)$ & $4.568(12.7)$ & $9.869(13.3)$ \\
\hline \multirow{5}{*}{ Chronic mental stress n (\%) } & Very high & $3.487(9.1)$ & $5.327(14.8)$ & $8.814(11.9)$ \\
\hline & High & $9.853(25.8)$ & $12.699(35.3)$ & $22.552(30.4)$ \\
\hline & Normal & $16.638(43.5)$ & $13.764(38.3)$ & $30.402(41)$ \\
\hline & Low & $6.768(17.7)$ & $3.723(10.4)$ & $10.491(14.1)$ \\
\hline & Very low & $1.475(3.9)$ & $452(1.3)$ & $1.927(2.6)$ \\
\hline \multirow{5}{*}{ Family economic status n (\%) } & Very rich & $3.085(8.1)$ & $1.698(4.7)$ & $4.783(6.4)$ \\
\hline & Rich & $9.498(24.9)$ & $8.001(22.2)$ & $17.499(23.6)$ \\
\hline & Average & $17.185(45)$ & $17.699(49.2)$ & $34.884(47)$ \\
\hline & Poor & $6.407(16.8)$ & $6.806(18.9)$ & $13.213(17.8)$ \\
\hline & Very poor & $2.046(5.4)$ & $1.761(4.9)$ & $3.807(5.1)$ \\
\hline \multirow{4}{*}{ Father's education level n (\%) } & Unknown & $7.092(18.6)$ & $6.153(17.1)$ & $13.245(17.9)$ \\
\hline & Middle school or lower & $1.66(4.3)$ & $1.548(4.3)$ & $3.208(4.3)$ \\
\hline & High school & $12.769(33.4)$ & $12.752(35.5)$ & $25.521(34.4)$ \\
\hline & College or higher & $16.7(43.7)$ & $15.512(43.1)$ & $32.212(43.4)$ \\
\hline \multirow{4}{*}{ Mother's education level n (\%) } & Unknown & $7.453(19.5)$ & $5.376(14.9)$ & $12.829(17.3)$ \\
\hline & Middle school or lower & $1.576(4.1)$ & $1.562(4.3)$ & $3.138(4.2)$ \\
\hline & High school & $15.976(41.8)$ & $16.736(46.5)$ & $32.712(44.1)$ \\
\hline & College or higher & $13.216(34.6)$ & $12.291(34.2)$ & $25.507(34.4)$ \\
\hline \multirow{7}{*}{ Smoking frequency n (\%) } & Non-smoker & $31.973(83.7)$ & $33.851(94.1)$ & $65.824(88.7)$ \\
\hline & $1-2$ day(s) per month & $1.092(2.9)$ & $500(1.4)$ & $1.592(2.1)$ \\
\hline & $3-5$ days per month & $485(1.3)$ & $229(0.6)$ & $714(1)$ \\
\hline & 6-9 days per month & $404(1.1)$ & $153(0.4)$ & $557(0.8)$ \\
\hline & 10-19 days per month & $570(1.5)$ & $193(0.5)$ & $763(1)$ \\
\hline & 20-29 days per month & $602(1.6)$ & $197(0.5)$ & $799(1.1)$ \\
\hline & Daily & $3.095(8.1)$ & $842(2.3)$ & $3.937(5.3)$ \\
\hline \multirow{7}{*}{ Drinking frequency n (\%) } & Non-drinker & $29.594(77.4)$ & $30.269(84.2)$ & $59.863(80.7)$ \\
\hline & 1-2 day(s) per month & $4.773(12.5)$ & $3.619(10.1)$ & $8.392(11.3)$ \\
\hline & $3-5$ days per month & $1.745(4.6)$ & $1.054(2.9)$ & $2.799(3.8)$ \\
\hline & 6-9 days per month & $984(2.6)$ & $461(1.3)$ & $1.445(1.9)$ \\
\hline & 10-19 days per month & $673(1.8)$ & $336(0.9)$ & $1.009(1.4)$ \\
\hline & 20-29 days per month & $298(0.8)$ & $150(0.4)$ & $448(0.6)$ \\
\hline & Daily & $154(0.4)$ & $76(0.2)$ & $230(0.3)$ \\
\hline
\end{tabular}




\begin{tabular}{llll}
\hline \multicolumn{5}{c}{ Data are expressed as mean $\pm \mathrm{SD}$ or $\mathrm{n}(\%)$} & \multicolumn{1}{c}{ Total $(\mathrm{N}=74,186)$} \\
\hline \multicolumn{5}{c}{ Variables } & \multicolumn{1}{c}{ Grequency of vigorous physical activity per week $\mathrm{n}(\%)$} \\
\hline None & $5.656(14.8)$ & $14.57(40.5)$ & $20.229(27.3)$ \\
Once & $6.803(17.8)$ & $8.282(23.0)$ & $15.085(20.3)$ \\
Twice & $7.938(20.8)$ & $6.044(16.8)$ & $13.982(18.8)$ \\
3 times & $6.759(17.7)$ & $3.614(10)$ & $10.373(14)$ \\
4 times & $3.501(9.2)$ & $1.390(3.9)$ & $4.891(6.6)$ \\
5 times or more & $7.561(19.8)$ & $2.065(5.7)$ & $9.626(13)$ \\
\hline \multicolumn{5}{c}{ Frequency of moderate physical activity per week n (\%) } \\
\hline None & $6.937(18.1)$ & $11.886(33)$ & $18.823(25.4)$ \\
Once & $7.776(20.3)$ & $8.942(24.9)$ & $16.718(22.5)$ \\
Twice & $8.247(21.6)$ & $7.046(19.6)$ & $15.293(20.6)$ \\
3 times & $6.334(16.6)$ & $4.274(11.9)$ & $10.608(14.3)$ \\
4 times & $2.872(7.5)$ & $1.582(4.4)$ & $4.454(6)$ \\
5 times or more & $6.055(15.8)$ & $2.235(6.2)$ & $8.290(11.2)$ \\
\hline \multicolumn{5}{c}{ Frequency of muscular strength exercises per week $\mathrm{n}(\%)$} \\
\hline None & $14.062(36.8)$ & $24.274(67.5)$ \\
Once & $7.807(20.4)$ & $5.720(15.9)$ & $38.336(51.7)$ \\
Twice & $5.542(14.5)$ & $2.682(7.5)$ & $13.527(18.2)$ \\
3 times & $4.338(11.3)$ & $1.551(4.3)$ & $8.224(11.1)$ \\
4 times & $1.894(5)$ & $604(1.7)$ & $5.889(7.9)$ \\
5 times or more & $4.578(12)$ & $1.134(3.2)$ & $2.498(3.4)$ \\
\hline
\end{tabular}

Data are expressed as $\mathrm{n}(\%)$

Source: own work

Science and Technology, Ministry of Health and Welfare, Korea Centers for Disease Control and Prevention, 2012). The KYRBWS has been shown to have good validity and reliability (Bae et al., 2010a, 2010b).

\section{Dependent variable}

Academic performance was evaluated using the following question: "How well do you believe you are performing at school?" There were five available responses: [1] excellent, [2] good, [3] mediocre, [4] poor, and [5] very poor. For our multivariate logistic regression, we divided participants into 2 groups according to their responses to the question: [a] below average academic performance (i.e., responses of poor and very poor; this served as the reference group) and [b] average academic performance or higher (i.e., responses of excellent, good, or mediocre).

\section{Independent variable}

Chronic mental stress was evaluated for each participant with the following question: "In general, how much mental stress do you feel on a regular basis?" The response options included [1] very high mental stress, [2] high mental stress, [3] normal mental stress, [4] low mental stress, and [5] very low mental stress. In addition, the primary cause of participants' chronic mental stress was evaluated using another question: "What is the primary cause of your chronic mental stress?" Participants could choose one of the following: [1] conflicts with parents (interference, discrimination, excessive expectations, indifference, abuse); [2] family circumstances (economic problems, environment, parents fighting, separation, divorce); [3] conflicts with teachers; [4] friends (fighting, bullying, peer relationships, dating, conflicts with friends); [5] grades (tests, entrance examinations); [6] health 
problems; [7] appearance (height, body shape, facial features)and [8] other.

\section{Covariate variables}

We also assessed a number of covariates to ensure that we identified the direct relationship between chronic mental stress and academic performance. These included age, body mass index, family economic status, parents' education level, smoking and drinking frequency, frequency of vigorous and moderate physical activity (PA), and frequency of muscular strength exercises.

Participants' ages were taken from the KYRBWS-VIII data without any modifications. We used participants' self-recorded height and weight to calculate the body mass index $(\mathrm{kg} / \mathrm{m} 2)$. For family economic status, the possible responses ranged from 1 ("very rich") to 5 ("very poor"). For parents' education level, the possible responses were 1 ("middle school or lower"), 2 ("high school"), 3 ("college or higher"), and 4 ("unknown"). Smoking and drinking frequency responses could range from 1 (no smoking/drinking) to 7 (smoking/drinking daily).
Vigorous PA included activities such as digging, aerobics, heavy lifting, or fast cycling during the week, and possible responses ranged from 1 ("none") to 6 ("5 times a week or more"). Moderate PA offered the same responses, but included activities such as bicycling at a regular pace, carrying light loads, or playing doubles tennis during the week. Finally, muscular strength exercises included sit-ups, pushups, and weight lifting or weight training, and the frequency that participants engaged in these activities was assessed by their responses on a scale ranging from 1 ("none") to 6 ("over 5 days") (Table 1).

\section{Statistical analysis}

The descriptive statistics of the study are expressed as means (SD) or frequencies (\%). Multivariate logistic regression analyses were conducted to determine whether chronic mental stress was related to academic performance, after adjusting for the covariate variables. Chi-square tests were used to test whether boys and girls differed in their primary causes of chronic mental stress. If the expected frequency counts in the chi-square test were less than

\section{TABLE 2}

The Results of the Multivariate Logistic Regression Analysis for Academic Performance in Relation to Chronic Mental Stress in Korean Adolescents $(N=74,186)$

\begin{tabular}{llcccc}
\hline \multicolumn{2}{c}{ Chronic mental stress } & \multicolumn{4}{c}{$\begin{array}{c}\text { Below-average academic performance vs. } \\
\text { Average academic performance or higher }\end{array}$} \\
\hline \multirow{2}{*}{ Boys } & Case & OR & $95 \%$ CI & p-value \\
& Very low & 1.475 & Reference & \\
& Low & 6.768 & 1.131 & $0.988-1.296$ & 0.075 \\
& Average & 16.638 & 1.075 & $0.945-1.222$ & 0.273 \\
& High & 9.853 & 0.916 & $0.808-1.037$ & 0.166 \\
& Very high & 3.487 & 0.738 & $0.629-0.867$ & $<0.001^{* * *}$ \\
\hline \multirow{6}{*}{ Girls } & Very low & 452 & Reference & & \\
& Low & 3.723 & 1.324 & $1.029-1.704$ & $0.029^{*}$ \\
& Average & 13.764 & 0.992 & $0.779-1.263$ & 0.948 \\
& High & 12.699 & 0.808 & $0.634-1.03$ & 0.086 \\
& Very high & 5.327 & 0.668 & $0.521-0.857$ & $0.002^{* *}$ \\
\hline
\end{tabular}

$\mathrm{SE}=$ standard error. $\mathrm{OR}=$ odds ratio. $\mathrm{CI}=$ confidence interval

$* p<0.05 * * p<0.01 * * * p<0.001$. Tested by multivariable logistic regression analysis after adjustment for age, body mass index, family economic status, parents' education level, smoking frequency, alcohol drinking frequency, and frequency of vigorous and moderate physical activity as well as muscular strength exercises.

Source: own work 
5, a Fisher's exact test was performed. The analyses were performed using SPSS Complex Sample ${ }^{\mathrm{TM}}$ version 18.0 (Chicago, IL, USA) and statistical significance was set at $p<0.05$.

\section{Results}

The characteristics of participants are shown in Table 1. The results of the multivariate logistic regression analyses for how academic performance related to chronic mental stress are shown in Table 2. For boys, the odds ratios (ORs; $95 \%$ confidence interval [CI]) for achieving average academic performance or higher by chronic mental stress level (with very low mental stress as the reference) were as follows: low mental stress, 1.131 (0.988-1.196; $p$ = 0.075); normal mental stress, 1.075 (0.945-1.222; $p=0.273)$; high mental stress, 0.916 (0.808-1.037; p $=0.166)$; and very high mental stress, 0.738 (0.629. $0.867, p<0.001)$. Thus, boys with very high mental stress were significantly less likely to have average academic performance or higher, compared with boys with very low mental stress.

For girls, the ORs for achieving average academic performance or higher by chronic mental stress level (with very low mental stress as the reference) were as follows: low mental stress, 1,324
(1.029-1.704; $p=0.029)$; normal mental stress, $0.992(0.779-1.263 ; p=0.948)$; high mental stress, $0.808(0.634-1.03 ; p=0.086)$; and very high mental stress, $0.668(0.521-0.857, p=0.002)$. In other words, girls with very high mental stress were significantly less likely, and those with low mental stress were significantly more likely, to have average academic performance or higher, compared with girls with very low stress.

The results of the chi-square test between boys and girls to determine the primary causes of chronic mental stress are shown in Table 3. Although boys and girls significantly differed among some of the primary causes of chronic mental stress $(p<$ 0.001 ), grades (tests, entrance examinations) were the biggest cause of chronic mental stress in both boys $(51.7 \%)$ and girls (54.8\%).

\section{Discussion}

The purpose of the present study was to examine the association between chronic mental stress and academic performance among Korean adolescents. We found that boys and girls with very high chronic mental stress were 0.738 and 0.668 times, respectively, as likely to have good academic performance as participants with very low chronic mental stress.

TABLE 3

The Differences between Boys and Girls in Primary Cause of Chronic Mental Stress

\begin{tabular}{lccc}
\hline & $\begin{array}{c}\text { Boys } \\
(n=38,221)\end{array}$ & $\begin{array}{c}\text { Girls } \\
(n=35,965)\end{array}$ & $\mathrm{p}$ \\
\hline $\begin{array}{l}\text { (1) Conflicts with parents (interference, discrimination, excessive } \\
\text { expectations, indifference, abuse) }\end{array}$ & $6312(16.5)$ & $4846(13.4)$ & \\
$\begin{array}{l}\text { (2) Family circumstances (economic problems, environment, parents } \\
\text { fighting, separation, divorce) }\end{array}$ & $1749(4.6)$ & $1715(4.8)$ & \\
(3) Conflicts with teachers & $1256(3.3)$ & $646(1.8)$ & \\
(4) Friends (fighting, bullying, peer relationship, dating, conflicts with & $3236(8.5)$ & $3688(10.3)$ & $<0.001^{* * *}$ \\
friends) & $19,789(51.7)$ & $19,739(54.8)$ \\
(5) Grades (tests, entrance examinations) & $946(2.5)$ & $422(1.2)$ \\
(6) Health problems & $3458(9.0)$ & $4457(12.4)$ & \\
(7) Appearance (height, body shape, facial features) & $1475(3.9)$ & $452(1.3)$ & \\
(8) Other & &
\end{tabular}

Data are expressed as $n(\%)$

*** $p<0.001$; Tested by chi-square tests.

Source: own work 
Previous studies have shown that mental stress affects cognitive function (Lupien et al., 2007; Marin et al., 2011). Researchers have offered a number of explanations for this. First, hormones such as adrenocorticotropic hormones and glucocorticoids are elevated in people experiencing mental stress. These elevated hormone levels are linked with memory impairments in learning; in particular, declarative errors-the frequency of mistakes on both immediate and delayed recall of information when people read a paragraphcan increase with higher levels of glucocorticoids (Newcomer, Craft, Hershey, Askins, \& Bardgett, 1994; Wolkowitz et al., 1990). Second, chronic mental stress is closely linked to learning and memory deficits in the hippocampus and cerebellum (Newcomer et al., 1994). Finally, mental stress appears to disrupt hippocampal-dependent cognition, which is related to memory function (McEwen \& Sapolsky, 1995).

Academic performance is highly related to skills in speaking, listening, writing, reading, and understanding, which in turn are governed by cognitive function. The results of this study indicated that Korean adolescents with high chronic mental stress are predisposed towards having below average academic performance.

Interestingly, even though boys and girls showed significantly different patterns in the primary causes of their chronic mental stress $(p$ $<0.001$ ), both groups reported that grades (tests, entrance examinations) were the primary cause of their chronic mental stress (Table 3). Because higher levels of chronic mental stress can lead to serious negative consequences, such as suicide attempts, in adolescents (Shaffer \& Craft, 1999), school programs and policies should focus on promoting stress management methods such as physical activity (Asztalos et al., 2009; Hamer, Stamatakis, \& Steptoe, 2009).

We must mention a few limitations. First, we were only able to assess the interrelationships between the variables because the KYRBWS-VIII is a cross-sectional retrospective cohort study; thus, the causal effects of chronic mental stress on academic performance could not be identified from our results. Second, some covariate variables, such as family economic status and parents' education level, were reported by the adolescents themselves and not by the parents, meaning that they could be inaccurate. Third, we were unable to directly measure participants' height and weight, meaning that the body mass index values may be somewhat lower than in reality, because many adolescents overestimate their height and underestimate their weight (Sherry, Jefferds, \& Grummer-Strawn, 2007). Finally, our main variables-chronic mental stress and academic performance-were self-reported, meaning that the values might not reflect actual mental stress or academic performance, and thus the true relationship between these factors may not have been determined in this study.

Despite these limitations, the present study offers results representing the whole population of adolescents in Republic of Korea, given its sample of 74,186 adolescents. This is a significant improvement over previous studies, which had much smaller sample sizes. Therefore, this study offers data with high external validity on the relationship between chronic mental stress and academic performance in Korean adolescents.

\section{Conclusion}

We concluded that for both boys and girls, very high chronic mental stress is associated with decreased academic performance. Furthermore, grades (tests, entrance examinations) appear to be the primary cause of chronic mental stress in both boys (51.7\%) and girls (54.8\%) in Republic of Korea.

\section{References}

Asztalos, M., Wijndaele, K., De Bourdeaudhuij, I., Philippaerts, R., Matton, L., Duvigneaud, N., ... Cardon, G. (2009). Specific associations between types of physical activity and components of mental health. Journal of Science and Medicine Sport, 12(4), 468-474.

Bae, J., Joung, H., Kim, J. Y., Kwon, K. N., Kim, Y., \& Park, S. W. (2010a). Validity of self-reported height, 
weight, and body mass index of the Korea Youth Risk Behavior Web-based Survey questionnaire. Journal of Preventive Medicine $\mathcal{E}$ Public Health, 43(5), 396-402.

Bae, J., Joung, H., Kim, J. Y., Kwon, K. N., Kim, Y., \& Park, S. W. (2010b). Test-retest reliability of a questionnaire for the Korea Youth Risk Behavior Web-based Survey. Journal of Preventive Medicine E3 Public Health, 43(5), 403-410.

Centers for Disease Control and Prevention (Mayo, 2005). Surviving field stress for first responders. Retrieved from http://www.atsdr.cdc.gov/emes/ surviving_stress/documents/TrainingWorkbookstress-editp1.pdf

Cohen, S., Janicki-Deverts, D., \& Miller, G. E. (2007). Psychological stress and disease. JAMA. The Journal of the American Medical Association, 298(14), 1685-1687.

Dimsdale, J. E. (2008). Psychological stress and cardiovascular disease. Journal of the American College of Cardiology, 51(13), 1237-1246.

Eiland, L., \& Romeo, R. D. (2012). Stress and the developing adolescent brain. Neuroscience, S0306-4522(12), 01072-X. doi:10.1016/j.neuroscience.2012.10.048

Hamer, M., Stamatakis, E., \& Steptoe, A. (2009). Doseresponse relationship between physical activity and mental health: the Scottish Health Survey. British Journal of Sports Medicine, 43(14), 1111-1114. Retrieved from http://www.atsdr.cdc.gov/emes/ surviving_stress/documents/TrainingWorkbookstress-editp1.pdf

Korea Ministry of Gender Equality \& Family (2012). 2012 statistics of adolescent. Seoul, Korea: Author. Lupien, S. J., Maheu, F., Tu, M., Fiocco, A., \& Schramek, T. E. (2007). The effects of stress and stress hormones on human cognition: Implications for the field of brain and cognition. Brain and Cognition, 65(3), 209-237.

Marin, M. F., Lord, C., Andrews, J., Juster, R. P., Sindi, S., Arsenault-Lapierre, G., ... Lupien, S. J. (2011). Chronic stress, cognitive functioning and mental health. Neurobiology of Learning and Memory, 96(4), 583-595.
McEwen, B. S., \& Sapolsky, R. M. (1995). Stress and cognitive function. Current Opinion in Neurobiology, 5(2), 205-216.

Ministry of Education, Science and Technology, Ministry of Health and Welfare, \& Korea Centers for Disease Control and Prevention (2012). The Eighth Korea Youth Risk Behavior Web-based Survey. Seoul, Korea: Authors.

Newcomer, J. W., Craft, S., Hershey, T., Askins, K., \& Bardgett, M. E. (1994). Glucocorticoid-induced impairment in declarative memory performance in adult humans. Journal of Neuroscience, 14(4), 2047-2053.

Pittenger, C., \& Duman, R. S. (2008). Stress, depression, and neuroplasticity: A convergence of mechanisms. Neuropsychopharmacology Review, 33, 88109.

Romeo, R. D., \& McEwen, B. S. (2006). Stress and the adolescent brain. Annals of the New York Academy of Sciences, 1094, 202-214.

Sanders, A. E, \& Lushington, K. (2002). Effect of perceived stress on student performance in dental school. Journal of Dental Education, 66(1), 75-81.

Shaffer, D., \& Craft, L. (1999). Methods of adolescent suicide prevention. Journal of Clinical Psychiatry, 60(Suppl. 2), 70-74.

Sherry, B., Jefferds, M. E., \& Grummer-Strawn, L. M. (2007). Accuracy of adolescents self-report of height and weight in assessing overweight status. Archives of Pediatrics $\mathcal{E}$ Adolescent Medicine, 161(12), 1154-1161.

Stewart, S. M., Lam, T. H., Betson, C. L., Wong, C. M., \& Wong, A. M. (1999). A prospective analysis of stress and academic performance in the first two years of medical school. Medical Education, 33(4), 243-250.

Wolkowitz, O. M., Reus, V. I., Weingartner, H., Thompson, K., Breier, A., Doran, A., ... Pickar, D. (1990). Cognitive effects of corticosteroids. American Journal of Psychiatry, 147(10), 1297-1303.

Xu, L., Anwyl, R., \& Rowan, M. J. (1997). Behavioral stress facilitates the induction of long-term depression in the hippocampus. Nature, 387, 497-500. 